\title{
Shooting Simulator for Fluvial Combat Training
}

Carlos F. Rodríguez ${ }^{1}$

José Tiberio Hernández ${ }^{2}$

Pablo Figueroa ${ }^{3}$

\begin{abstract}
Virtual shooting training has become very attractive because of possible cost reductions and precise evaluation. This article describes the development of a shooting simulator to train soldiers in fluvial combat. This simulator combines the motion of a mechanical platform with virtual imagery and sound to produce an immersive scenario for training purposes. Our prototype, which is in its last phase of construction, has four training tasks with three levels of difficulty. Initially, each task is defined in terms of a virtual trajectory, used by our custom-based motion platform to produce realistic movements, based on a simple dynamic model from real measurements. Our visualization, sound effects, and metrics are implemented on the Torque game engine. Finally, a postprocessor system computes a metrics report.
\end{abstract}

Key words: Motion simulation platform, virtual training, virtual reality.

\section{Resumen}

El entrenamiento de tiro virtual se ha vuelto muy atractivo debido a las posibles reducciones de costos y a la evaluación precisa. Este artículo describe el desarrollo de un simulador para entrenamiento de soldados en combate fluvial. El simulador combina el movimiento de una plataforma mecánica con imágenes virtuales y sonido para producir un escenario de inmersión con propósitos de formación. Nuestro prototipo, que se encuentra en su última fase de construcción, tiene cuatro tareas con tres niveles de dificultad. Inicialmente, cada tarea es definida en términos de una trayectoria virtual usada por nuestra plataforma de movimiento personalizado para reproducir movimientos reales, basado en un modelo de dinámica simple a partir de mediciones reales. Nuestra visualización, efectos de sonido, y métricas son implementados en el motor de juegos Torque. Finalmente, un sistema de post-procesamiento calcula un informe de medidas.

Palabras claves: Plataforma de simulación de movimiento, entrenamiento virtual, realidad virtual.

Date Received: October 24th, 2010 - Fecha de recepción: 24 de Octubre de 2010

Date Accepted: January 16th, 2012 - Fecha de aceptación: 16 de Enero de 2012

\footnotetext{
${ }^{1}$ Facultad de Ingeniería, Universidad de los Andes. Bogotá, Colombia. e-mail: crodrigu@uniandes.edu.co

${ }^{2}$ Facultad de Ingeniería, Universidad de los Andes. Bogotá, Colombia. e-mail: jhernand@uniandes.edu.co

${ }_{3}^{3}$ Facultad de Ingeniería, Universidad de los Andes. Bogotá, Colombia. e-mail: pfiguero@uniandes.edu.co
} 


\section{Introduction}

The recent armed conflict situation in Colombia has forced the National Naval Force (Armada Nacional de la República de Colombia, $A R C$ ) to develop special abilities to battle in rivers. Almost half of the Colombian territory is jungle and most of this vast area can be cruised by rivers. Jungle areas are used by guerrillas and illegal drug producers. Therefore, ARC is very motivated to develop tactics, equipment, and training for its troops in fluvial combat. As a result, ARC has become a worldwide leader in fluvial combat.

The basic ability of a soldier is to shoot different guns with precision. The use of virtual tools for shooting training has advantages in cost reduction (less ammunition used) and in evaluation metrics (many conditions can be controlled and monitored). There are many commercial products available for shooting training, although most of them are not adequate for shooting training from a moving vehicle.

Moreover, motion simulation platforms are nowadays widely used to replicate the dynamics of a given vehicle to train different users with lower costs and risks than real training. This is the case of combat boats in which users must train to get used to the unanticipated motions of the boat while ensuring good performance in their combat tasks.

This paper presents the development of a shooting simulator for fluvial combat. The simulator combines the motion of a mechanical platform with virtual imagery and sound to produce an immersive scenario for training. The general conception of the simulator is explained first. The following three sections describe the mechanical platform, the simulation software and the postprocessor.

\section{General Concepts of the Simulator}

The simulator is based on the use of a dynamic simulator in a virtual reality environment. The dynamic simulator is a custom-built robotized platform with three degrees of freedom that reproduces the motion of the boat (Fig. 1).
Fig 1. Robotized mechanical platform

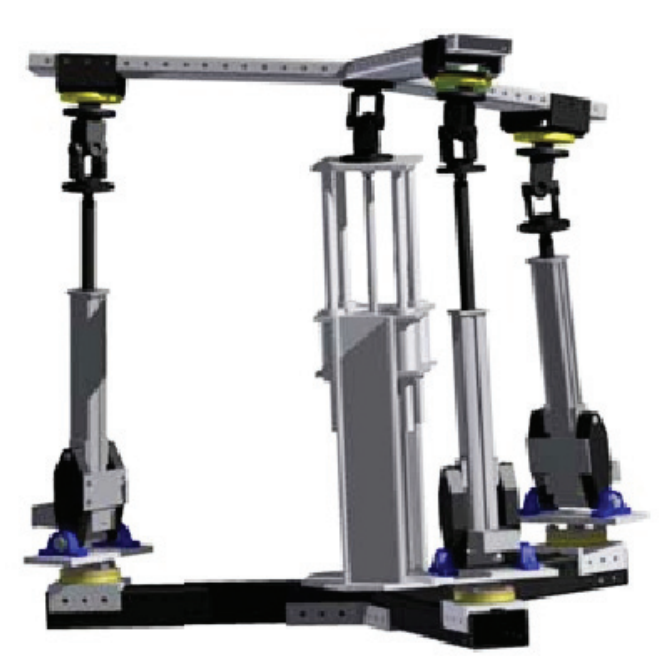

The shooting training site is installed over this platform. It is composed of a section of the hull of the boat, the back part of the gun (including the trigger), and a 55-inch monitor where virtual images are displayed (Fig. 2). The system is complemented with virtual audio effects. This site is adaptable for two types of guns and shooter poses: an M2 rifle (0.50) for a standing shooter and an M60 rifle for a seated shooter. The gun mockup is instrumented; thus enabling the measurement of events like shooting (trigger), aiming direction (one encoder for elevation and one for orientation), unlocking (micro switch), gun reloading (micro switch) and relative position of the gun and the shooter (photocell).

The simulator is programmed for a set of training tasks: preparation, flank changing, target identification, target shooting and gun reloading. Each task can be run in three difficulty levels: tutorial, normal, and combat. Several parameters can be selected for each training session such as daytime, weather, location, number of enemies, and behavior.

The core of our simulator development is the feedback on the user's progress. A postprocessor identifies the user's actions from events in a training task. Evaluation criteria for task fulfillment are efficiency (use of resources), adherence to military doctrine, discipline under attack, along with rules of engagement and safety. The metrics associated to 
Fig 2. Shooting training site

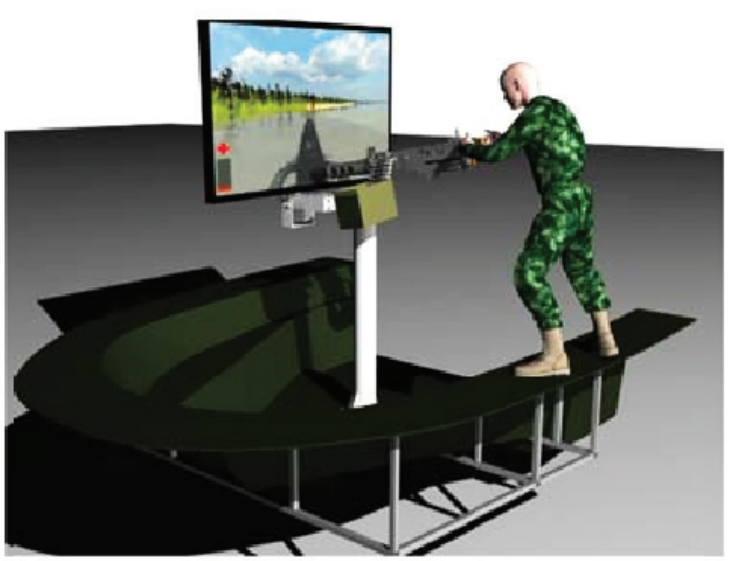

each criterion are computed by the postprocessor. Examples of these measured variables are: time to perform an action (reload the gun, aim at the target, etc.), number of bullets used, variation of aiming with boat in motion, and adherence to a predefined sequence of actions.

\section{Mechanical Platform}

To resemble a boat's typical maneuvers, a 3-DOF parallel robot with a passive mass compensator (3UPS+PU) was developed (Fig. 3).

Fig 3. 3 UPS + PU platform

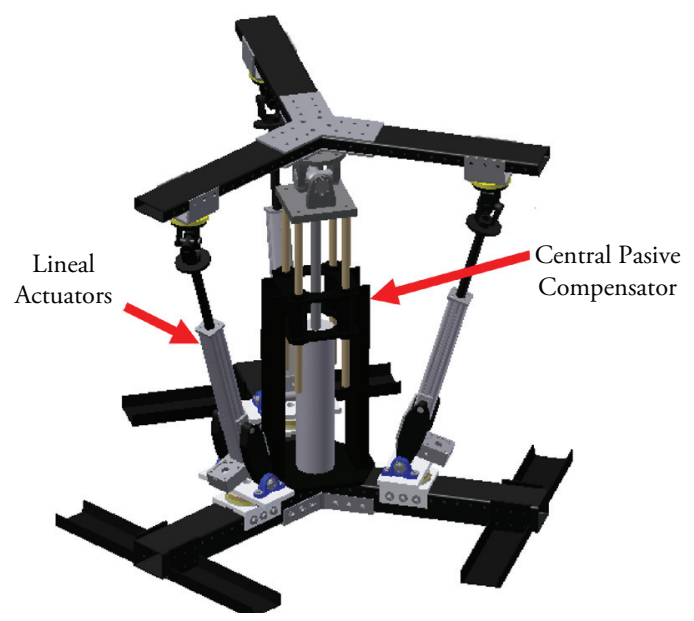

This robot permits three uncoupled degrees of freedom of the upper platform: roll, pitch, and vertical displacement (heave). It is driven by three electrically actuated prismatic limbs. The passive mass compensator consists of a pneumatic actuator that keeps a constant vertical force and restrains the other DOF's by an additional prismatic structure. The compensator is fixed to the lower platform and coupled to the upper platform by a universal joint.

After an optimization procedure, the configuration of the limbs and the position of the shooting training site were selected. This procedure minimizes the average force of each actuator during a training session. Fig. 4 shows the final mechanical configuration of the simulator.

Fig 4. Mechanical configuration of the simulator
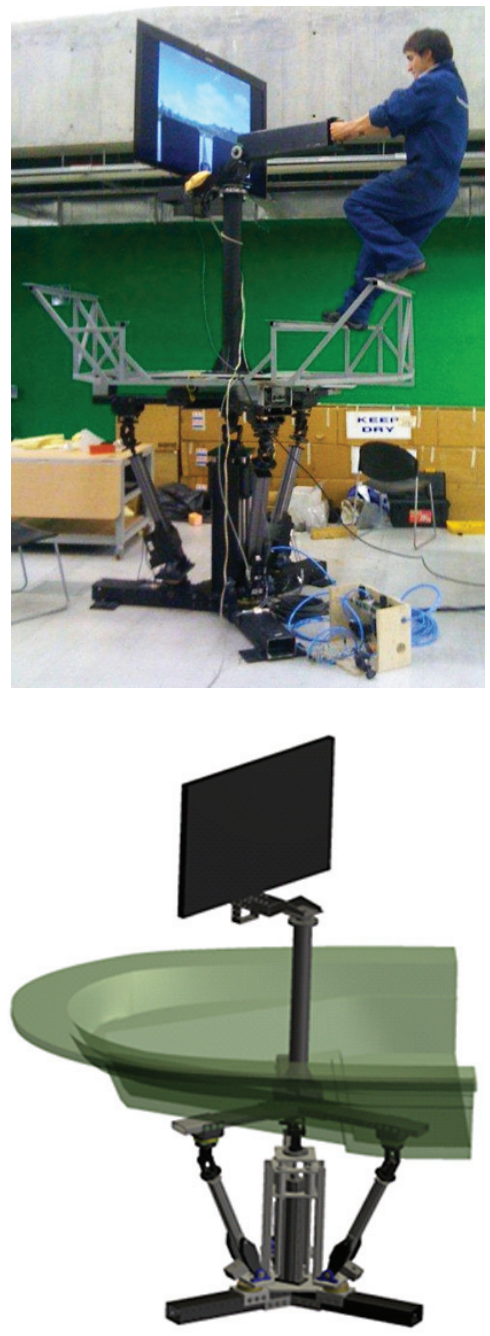

Three Yaskawa, 800-watt servomotors with Exlar actuators were used for the robotized platform. The motion control is performed with a Yaskawa controller SMC-4000. This controller allows 
communication via Ethernet with the simulation computer for synchronization purposes.

\section{Simulation Software}

The game engine Torque was used to develop the virtual scenario and to process events of a training session. This engine enables the definition of training terrain, the definition of the boat's path, the definition of behavior for objects in the scenario (enemies, civilians, other boats, etc.), the simulation of events (shooting, impact, tracer bullets, enemy bullets, etc.), the simulation of light and weather conditions, and the visualization from different points of view (user, boat, etc).
Our procedure for terrain definition is as follows (Fig. 5). It begins with a rough specification of the geography of the river and its surroundings. Then the sky and details of the river basins are added. Finally, the vegetation (grass, trees, etc.) complete the terrain.

Once the terrain is generated, the next step is to define possible training tasks on it. This process is similar to the specification of a storyboard. Fig. 6 shows a terrain and a schematic definition of a task sequence, in terms of a boat's path. This definition was made by ARC officers with broad experience in combat and training. It is translated into a sequence and saved in the simulation data base. This operation needs the definition of the boat's

Fig 5. Procedure of terrain definition
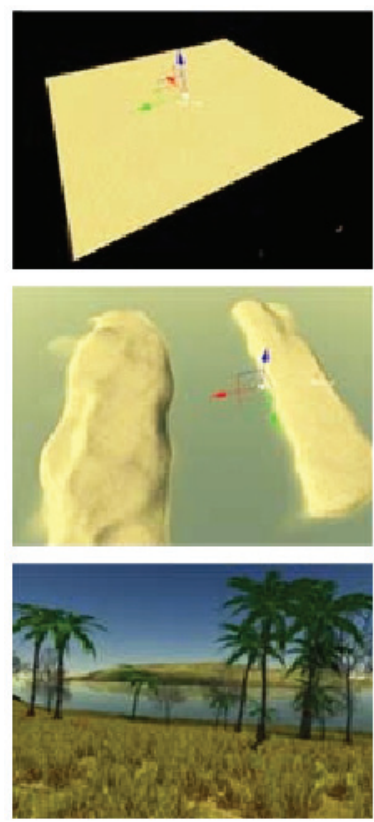
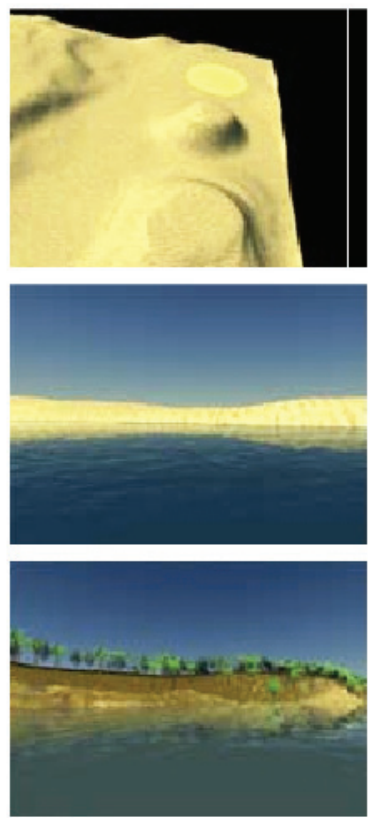
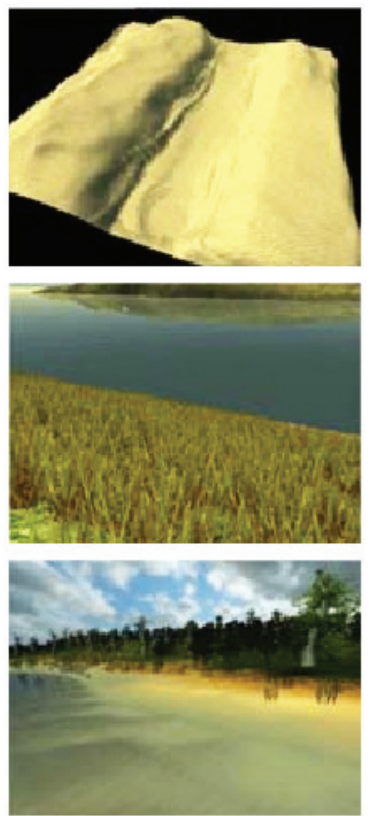

Fig 6. Task sequence and boat's path definition
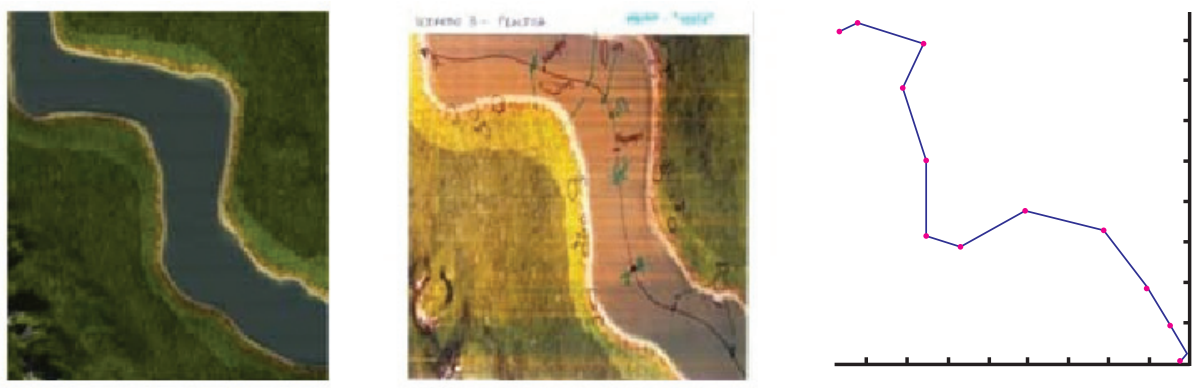
path and the association of tasks to each path's segment.

Two more elements are required to complete a simulation scenario for a training session: a context and a set of dynamic objects. The context is defined by the following set of variables: daytime, weather, type of gun, training level (tutorial, normal, combat), and mean velocity of the boat. Dynamic objects are entities with a body and a behavior. These include enemies, civilians, groups of people, other boats, etc. The behavior includes autonomous actions like moving and shooting, and the specification of triggers for the action (for example, hide if a bullet hits near the object, shooting back, etc.).

Thissoftwareiscomplementedwithcommunications with peripherals via Virtual Reality Peripheral Network (VRPN: 10.1145/505008.505019). By means of VRPN we defined a communication protocol with our mechanical platform and our gun. We also add sound in order to create a more immersive experience.

Finally, a trajectory generator based on a simplified dynamic model of the boat's motion completes the simulator software. It receives as input the path and the the boat's mean velocity and it produces a number of variations of the trajectories of the boat. The trajectories differ in few random parameters, introducing variety in case of repetition of the training sessions.

The dynamic model was uncoupled by planes. Fig. 7 shows some degrees of freedom of the boat's motion and the coordinate systems used for the model derivation.

Fig 7. Coordinate systems for model derivation

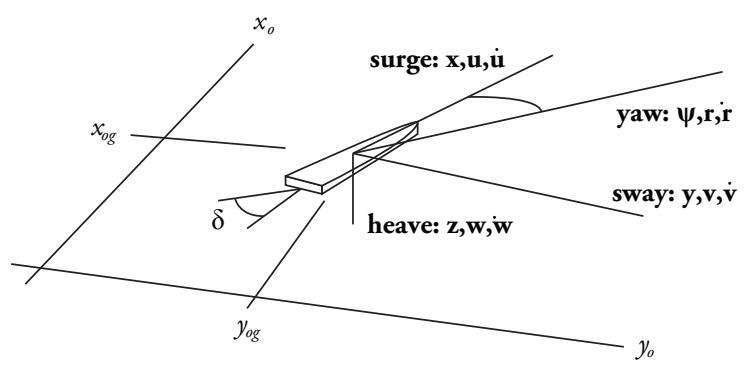

The horizontal plane model considers the surge, sway, and yaw and it is a linearized model of the Newton equations applied to the boat:

$$
\begin{aligned}
& X=m \dot{u} \\
& Y=m(\dot{v}+u r) \\
& N=I_{z} \dot{r}
\end{aligned}
$$

where $X, Y$ and $N$ are force in the $x$ direction, force in the $y$ direction, and torque around $z$ direction, respectively, $u$ is the forward velocity, $v$ is the lateral velocity, and $r$ is the angular velocity of the boat. Rewriting the equations with respect to the midship point, we have:

$$
\begin{aligned}
& X=m \dot{u} \\
& Y=m\left(v+u r+x_{g} r\right) \\
& N=I_{z} \dot{r}+m x_{g} \dot{u}
\end{aligned}
$$

In general, $Y=Y(u, v, r, \dot{u}, \dot{v}, \dot{r})$ and the same is true for $X$ and $N$. So using a first-order approximation

$Y=\Delta u \frac{\partial Y}{\partial u}+\Delta v \frac{\partial Y}{\partial v}+\Delta r \frac{\partial Y}{\partial r}+\Delta \dot{u} \frac{\partial Y}{\partial \dot{u}}+\Delta \dot{v} \frac{\partial Y}{\partial \dot{v}}+\Delta \dot{r} \frac{\partial Y}{\partial \dot{r}}$

Due to the symmetry of the boat, the terms $\partial Y / \partial u$ and $\partial Y / \partial \dot{u}$ are null. Using the short notation $\partial Y / \partial v=Y_{v}$ the equation becomes

$$
Y=v Y_{v}+\dot{v} Y_{\dot{v}}+r Y_{r}+\dot{r} Y_{\dot{r}}
$$

Similarly, for the torque $N$

$$
N=v N_{v}+\dot{v} N_{\dot{v}}+r N_{r}+\dot{r} N_{r}
$$

The partial derivatives $(Y, Y$, etc., $)$ in the preceding equations are called hydrodynamic derivatives, stability coefficients or hydrodynamic coefficients.

The following is the set of linearized dynamic equations of motion: 


$$
\begin{aligned}
& X_{u}\left(u-u_{1}\right)+\left(m-X_{x g}\right) \dot{u}=P \operatorname{Cos} \delta \\
& -Y_{v} v+\left(m-Y_{\dot{v}}\right) \dot{v}-\left(Y_{r}-m u_{1}\right) r-\left(Y_{r}-m x_{g}\right) \dot{r}=P \operatorname{Sin} \delta \\
& -N_{v} v+\left(N_{\dot{v}}-m x_{g}\right) \dot{v}-\left(N_{r}-m x_{g} u_{1}\right) r+\left(I_{z}-N_{r}\right) \dot{r}=L_{p} P \operatorname{Sin} \delta
\end{aligned}
$$

where $P$ is the propulsion force, $\delta$ is the angle between this force and the $x$ axis of the boat and $L_{p}$ is the length from the origin of the coordinate system fixed in the boat and the point of application of the propulsion force. The hydrodynamic coefficients were taken from literature and Computational Fluid Dynamics (CFD) simulations and verified experimentally.

The description of the vertical motion is approximated by a series of harmonics that resemble the spectrum of frequencies of the boat's motion. We used measurements on a real boat, during a set of typical maneuvers. Both models were implemented in MATLAB/SIMULINK for the computation of trajectories.

\section{Postprocessor}

Log data of training sessions is downloaded to a data base for post processing. Three main routines were implemented for the evaluation of user performance: a collision detector, a metrics calculator, and a report generator.

The collision detector allows the identification of an impact point of every shot during the training session. If the session includes tasks of target identification (without shooting), this routine also computes the line of action of potential shots. Fig. 8 shows the concept of this routine. Large circles represent constructions, while the small circles represent people. The medium circle represents another boat.

In order to compute the aiming direction and the objects reachable by shots, the historical $\log$ of the session is revisited. Each object in the scene is surrounded by a sphere and a ray is projected departing from the gun for each instant of time in the training session. This information is then used to compute the metrics related to the task.
Fig 8. Collision detector computing in a given time instant

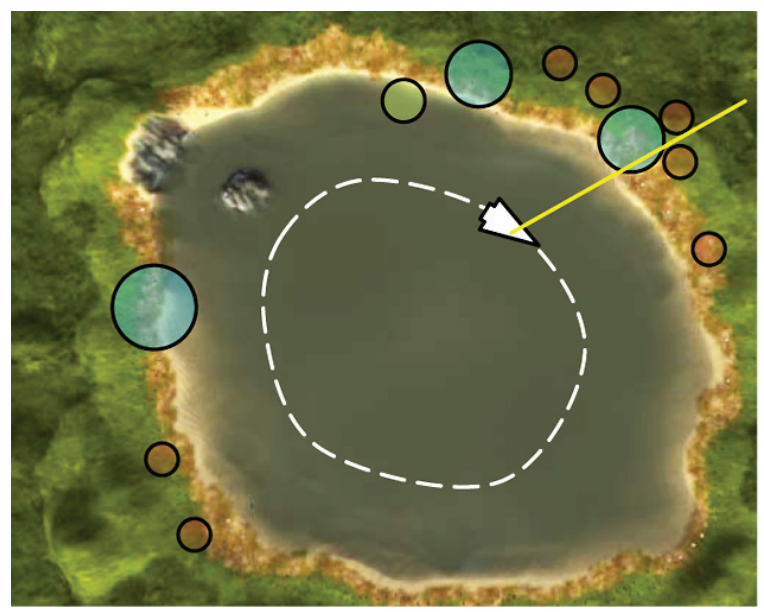

The next post-processing step is taken to segment the whole session into defined tasks. Each task of the training session should have occurred in a given portion of the path traveled by the boat. The $\log$ file contains the information of every event that occurred while traveling that portion of the path, so events are segmented and associated to the task under execution during that time.

By using the definition of metrics for each task, the corresponding variables are then quantified: number of actions, time until a given event, sequence of actions, etc. The measurement of these variables constitutes the basis for the evaluation of the user's performance.

Finally, a report for the session is automatically produced. The routine puts together user's identification information, historical data on his/ her training, and values of the metrics for the tasks in the training session.

An example of the report is shown in Fig. 9. The first section is the user and session identification data. Then, the percentage in time of each task during the session is presented, followed by the appropriate 
sequence of execution. Computed values of the variables for metrics are then included, and the

percentage of success in each task is depicted.

Fig 9. Example of the report generated for a training session

\section{$\underset{\text { sesion entrenamiento }}{\text { REPORTE }} 001$}

$15 / 12 / 2010$

Información de la sesión

INFORMACIÓN DEL INFANTE

Castro Martínez, David

Sargento Mayor de Comando

Brigada Fluvial No.1

Documento: 192782

Fecha de inicio: 01/01/2010

Horas de Entrenamiento: 2 Horas

Nivel de Entrenamiento: Tutorial

\section{INFORMACIÓN DEL ESCENARIO}

Zona: Putumayo

Condiciones de Luz

Hora: 19:00

Neblina: $10 \%$

Clima: Soleado

Recorrido: Velocidad: Media

Intensidad de Entrenamiento: 4

Dificultad del entrenamiento: 4

\section{INFORMACIÓN DE LA SESIÓN}

Fecha: $15 / 12 / 2010$

Duración: 00:04:25

Objetivos: Mejorar el empleo de la doctrina y la seguridad en la ejecucion de la tarea $\mathrm{e}$ identificacion de blancos.

Modo de Entrenamiento: Tutorial

Número de Repeticiones: 0

Entrenador: Ruiz Caballero, Felipe Documento entrenador: 19852963

\section{COMPOSICION DE LA SESIÓN}

Composición de la sesión según tareas

y repeticiones de cada tarea *ACIBRA

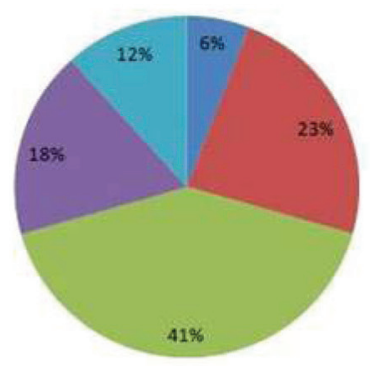

\section{OPERACIÓN - SECUENCIA DE TAREAS}

Las tareas programadas para cada sesión de entrenamiento asociadas a los segmentos de la trayectoria del bote.

\section{TIPOS DE TAREAS ( $\left.{ }^{*} \mathrm{ACIBRA}\right)$}

\section{A - Alistamiento (*1)}

C - Cambio de frente $\left({ }^{*} 3\right)$

I - Identificación de objetivo (*7)

B - Batir blanco $\left({ }^{*} 3\right)$

RA - Recargar arma (*2)
Orden de las tareas:

1. Alistamiento

2. Cambio de frente

3. Identificación de objetivo

4. Identificación de objetivo

5. Cambio de frente

6. Identificación de objetivo

7. Batir blanco

8. Recargar arma

9. Cambio de frente

10. Identificación de objetivo

11. Batir blanco

12. Identificación de objetivo

13. Batir blanco

14. Identificación de objetivo

15. Identificación de objetivo

16. Recargar arma 
$\underset{\substack{\text { Resibin entrenamiento } \\ \text { REP }}}{\operatorname{Ron}} 001$

DETALLE DE LA EJECUCIÓN DE LAS TAREAS

\begin{tabular}{|c|c|c|c|c|c|}
\hline \multicolumn{6}{|c|}{ 1. Alistamiento $(00: 00: 01)$} \\
\hline EFI_101 & EFI_102 & DOC__101 & DIS_101 & SEG_101 & SEG_102 \\
\hline 20 segundos & OK & $\mathrm{OK}$ & 0 disparos & $\mathrm{OK}$ & $20 \%$ \\
\hline
\end{tabular}

2. Cambio de frente (00:00:50)

\begin{tabular}{|c|c|c|c|c|c|c|c|}
\hline EF1_201 & EFI_202 & EFI_203 & DOC_201 & DOC_202 & DIS_201 & SEG_201 & SEG_202 \\
\hline 0.3 segundo5 & 2 segundos & OK & OK & OK & 0 disparos & OK & $0 \%$ \\
\hline
\end{tabular}

\begin{tabular}{|c|c|c|c|c|c|}
\hline \multicolumn{3}{|c|}{ 3. Identificación de objetivo $(00: 00: 55)$} \\
\hline EFI_301 & DOC_301 & DOC_302 & DIS_301 & REG_301 & SEG_301 \\
\hline 5 segundas & 3 segundos & true & 0 disparos & 0.5 segundos & 3 segundos \\
\hline
\end{tabular}

\begin{tabular}{|c|c|c|c|c|c|}
\hline \multicolumn{4}{|c|}{ 4. Identificación de objetivo $(00: 01: 00)$} \\
\hline EFI_303 & DOC_301 & DOC_302 & DIS_301 & REG_301 & SEG_301 \\
\hline 20 segundos & 0.1 segundo5 & false & 0 disparos & 0 segundos & 0.1 segundos \\
\hline
\end{tabular}

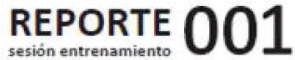

EVALUACIÓN

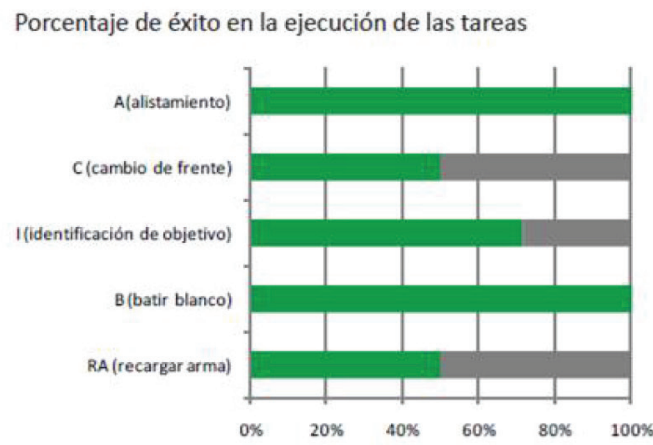

\section{Conclusions}

The conception and development of a shooting simulator for training in fluvial combat have been described. Starting from the definition of the set of combat tasks, a mechanical platform and simulation software have been combined to produce an immersive scenario for training.

The prototype permits training individual users by recreating the motion, view, and sound of the real boat. As the training scenario is fully controlled, a set of metrics to measure user progress is computed.
$15 / 12 / 2010$

Ejecución de la sesión

\section{Acknowledgements}

Once the prototype is finished, training tests will be conducted to test the level of realism of the experience and its effectiveness for developing the user's combat abilities.

The authors acknowledge the support given by the Research Division of the National Naval Force of Colombia (ARC) and the work by the project research team: Sergio Ordoñez, Juan Camilo Blanco, Luis Felipe Ramirez, Diana Fernandez, Raul Oses, Camilo Cortes, David Castro, Mauricio Parra, and Nicanor Quijano. 


\section{References}

BERTRAM, V. "Practical Ship Hydrodynamics". s.l. : Butterworth, Heineman.

BLANCO J.C., RODRIGUEZ C.F. "Configuration Optimization of a Boat Simulation Platform for a Mobile User", Proceedings of the ASME 2010 International Mechanical Engineering Congress \& Exposition, IMECE2010 November 2010, Vancouver, British Columbia, Canada.

CLARK J., KENDIR T., SHECHTER M., ROSA S., "Firearm Laser Training System And Method Employing An Actuable Target Assembly", Patent 6575753, USA, June 2003.

FALTINSEN, O. "Hydrodynamics of High-Speed Marine Vehicles". s.l. : Cambridge University Press, 2005.

GAO, F., LI, W., ZHAO, X., ZHENLIN, J., and HUI, Z., 2002, "New Kinematic Structures for 2-, 3-, 4-, and 5- DOF Parallel Manipulator Designs", Mechanism and machine theory, 37, pp. 1395-1411.

LVOVSKIY M., "Training Simulator For Sharp Shooting", Patent 6942486, USA, September 2005.

MASTINU, G., GOBBI, M., AND MIANO, C., 2006, Optimal Design of Complex Mechanical Systems. Springer-Verlag, Berlin, pp. 57-67. [8] Merlet, J. -P. 2006, Parallel Robots, Springer, Netherlands, pp. 19-93.

MONONEN K., VIITASALO J.T., ERA P., KONTTINEN N. "Optoelectronic Measures in the Analysis of Running Target Shooting", Scandinavian Journal of Medicine \& Science in Sports, Vol. 13, No. 3, 2003.

MORRISON G.B., "Police and Correctional Department Firearm Training Frameworks in Washington State", Police Quarterly, Vol. 6, No. 2, 2003.
PEREZ, T. "Ship motion control". London: Springer-Verlag, 2005.

POOR, CR. "Simulink Modeling of a Marine Autopilot for TSSE Shiip Designs". Master's Thesis, Naval Postgraduate School. Monterey, California: s.n., a996.

QUEVEDO L., SOLÉI J., "Visual Training Program Applied to Precision Shooting", Ophthalmic and Physiological Optics, Vol. 15, No. 5, September 1995.

SAUS E., JOHNSEN B.H., EID., RIISEM P.K., ANDERSEN R., THAYER.F., "The Effect of Brief Situational Awareness Training in a Police Shooting Simulator: An Experimental Study", Military Psychology, Vol. 18, No. 3, 2006

STAN, S.-D., MĂTIEŞ, V., AND BĂLAN, R., 2008, "Optimal Design of Parallel Kinematics Machines with 2 Degrees of Freedom", Parallel manipulators towards new applications, Wu, H., ed., I-Tech Education and Publishing, Vienna, pp. 295-320. n

SUZUKI K., "Shooting Game Machine", Patent 5366229, USA, November 1994. e

The Math Works, Inc. Genetic algorithm and direct search toolbox for use with MATLAB: user's g de (Version 1.0.1. ed.). The gui Math Works, c2004.

TSAI, L.-W. , 1999. Robot Analysis: The mechanics of Serial and Parallel Manipulators, John Wiley \& Sons, Inc, New York, Chap. 1.

WANG, Z.G; HU, Y.; XIE, F., "Optical Fiber Simulator for Shooting and Aiming Practices", Proc. SPIE VOL. 2895, The International Society for Optical Engineering, 1996.

ZAENGLEIN, JR. W.G., "Shooting Simulating Process and Training Device Using a Virtual Reality Display Screen", Patent 5641288, USA, June 1997. 